\title{
Reinventar la Educación Física como práctica social contra una tradición de violencia y de exclusión*
}

\author{
To reinvent the physical education as social practice against a tradition of \\ violence and exclusion \\ Reinventar a Educação Física como prática social contra uma tradição de \\ violência e exclusão
}

\begin{abstract}
Marcus Aurelio Taborda de Oliveira
Universidad Federal de Minas Gerais - Brasil. Consejo Nacional de Desarrollo Científico y Tecnológico CNPq, marcustaborda@pq.cnpq.br, 55.031.2514.3289
\end{abstract}

\begin{abstract}
RESUMEN
El presente artículo analiza las posibilidades de estudiar la Educación Física tanto como asignatura escolar cuanto como campo que refleja procesos contemporáneos, a partir de realizar una crítica de sus modos predominantes. Para ello se parte de reconocer el hecho histórico de que el desarrollo de la Educación Física en Latinoamérica, a raíz de tener como referencia los cánones de Europa y Estados Unidos, olvidó la rica gama de manifestaciones corporales locales de los diferentes países del continente. Estableciendo una base teórica argumentada en los estudios culturales y en la historia del currículum, este escrito reivindica la atención sobre la corporalidad como una posibilidad de cambiar tanto el pensamiento como la práctica de la Educación Física en la región. Desde esta perspectiva, la noción de "dialogismo", fundada en la posibilidad de construir un entre-lugar, resulta esencial para definir los nuevos parámetros sobre los cuales se procura erigir una Educación Física que combata la tradición de violencia y de exclusión que enmarca el continente.
\end{abstract}

Palabras clave: enseñanza de Educación Física, corporalidad y educación, Latinoamérica.

\begin{abstract}
This article aims to discuss the possibilities of physical education as school subject and field of study in contemporary processes from a critique of its prevailing modes. It starts from a historical verification that the physical education developed in Latin America, based on European and American canons, unconsidered the rich range of bodily possibilities from distinct countries of the continent. Supported by a theoretical basis grounded in cultural studies and history of curriculum, claims the attention to corporality as a possibility to resize the thought and the practice of physical education in the region. From this perspective the notion of dialogism, founded on the possibility of building a place in-between is essential to define the new parameters on which we can erect physical education against violence and exclusion characteristics of the continent.
\end{abstract}

Key words: teaching physical education, corporality and education, Latin America.

\section{RESUMO}

Analisam-se possibilidades de estudar Educação Física enquanto disciplina e enquanto um campo que reflete processos contemporâneos, a partir de uma crítica de modos dominantes. Para isso, parte-se do reconhecimento do eixo histórico em que se dá o desenvolvimento da Educação Física na América Latina, a raiz de se ter como referência modelos da

* Este articulo fue solicitado por la Revista Estudios Pedagógicos en diciembre del 2011 en el contexto del proyecto de Investigación FONDECYT (Fondo de Investigación Científica y Tecnológica) No 11110016 , titulado "Educación Física y su función de transformación de las desigualdades sociales: profesorado del área y documentación ministerial” Texto elaborado en el contexto del proyecto Fondecyt Na 11080297 
Europa e dos Estados Unidos, esquecendo-se da rica gama de manifestações corporais do local e dos diferentes países do continente. Estabelece-se uma base teórica pautada nos estudos culturais e na história do currículo, reivindicando atenção para a corporeidade como possibilidade de mudança tanto do pensamento como da prática da Educação Física na região. A partir desta perspectiva, a noção de "dialogismo", baseada na possibilidade de construir um entrelugar, é essencial à definição de novos parâmetros sobre os quais procura-se construir uma Educação Física que combata a tradição de violência e exclusão que marca o continente.

Palavras chave: ensino de Educação Física, corporeidade e educação, América Latina.

\section{INTRODUCCIÓN}

En este trabajo intento plantear algunos elementos que creo fundamentales para comprender la Educación Física y la formación en este campo disciplinar en relación a la complejidad de los tiempos actuales de exclusión, marca histórica que caracteriza la tradición latinoamericana. Aunque la idea misma de "Latinoamérica" sea una construcción llena de contradicciones, partimos de considerarla como una región compleja, múltiple y profundamente polifónica, pero que comparte innumerables experiencias de exclusión, violencia y autoritarismo.

Las reflexiones que aquí se esbozan surgen de comprender que la Educación Física, o mejor dicho la educación del cuerpo en distintos espacios sociales, se configura como una posibilidad de crítica radical de la cultura, una vez que se entiende que las prácticas corporales son eminentemente culturales, aún en aquellos discursos que reivindican la dimensión natural de las mismas. No olvidamos, como propone Raymond Williams, que "a ideia de natureza contém, embora muitas vezes de modo despercebido, uma quantidade extraordinária da história humana" (Williams, 2011: 89).

Así, me interesa reflexionar acerca de lo que se piensa o se dice sobre un mundo que se presume globalizado, donde la utopía de los universales -tan moderna- parece no tener mucho sentido. ¿O será que no es así? ¿Qué significa entonces para Latinoamérica reflexionar sobre la contribución de la Educación Física para una vida más digna para todos? Para ello se propone articular reflexiones de carácter teórico-historiográfico con una base empírica construida a raíz de las reflexiones realizadas en distintos proyectos de investigación llevados a cabo en los últimos diez años, tanto en Brasil cuanto por otras producciones surgidas del diálogo con investigadores argentinos, colombianos y uruguayos.

\section{EL SABER COMO PRODUCTO DE CONFLICTOS SOCIALES Y CULTURALES}

Muchas son las referencias a la comprensión del saber como artefacto social demarcado por disputas y conflictos. Siguiendo las huellas de Ivor Goodson (1995) en el ámbito de los estudios del curriculum, es posible comprender estos conflictos en el contexto de las corporaciones profesionales -en nuestro caso, educadores que tratan con y sobre la educación del cuerpo-, siendo imperativo reconocer que desde hace algunos años la complejidad es más grande. Afirmación que se sostiene en las grandes conquistas sociales y civiles, como la ampliación de derechos para las mujeres, los distintos grupos étnicos, los inmigrantes, los homosexuales; lo cual demuestra que la presencia de estos grupos en Latinoamérica, si bien evidente, fue históricamente relegada a lo largo de la historia.

Así, en la actualidad parece una contradicción sostener una asignatura como la Educación Física, en la cual no se les permita a las mujeres, por ejemplo, la práctica de 
determinadas actividades, juegos o deportes, o que sean tratadas como "menos hábiles" o poseedoras de una "motricidad menos competente". Lo mismo se puede decir de las poblaciones criollas, muy poco valoradas en los cánones oficiales de la Educación Física en nuestros países, los cuales vienen de tradiciones europeas distintas, con legados gimnásticos y deportivos "modernos" disímiles.

Si intentamos reescribir la historia de la Educación Física en términos menos prejuiciosos, entonces es necesario construir nociones como género y etnia que consideren estas dimensiones, pues los marcos tradicionales de la disciplina no dan cuenta de un mundo o de una sociedad donde los universales tienen cada vez menos espacio, y en donde lo que es humano se convierte en maquinaria. Así, si recuperamos la utopía del iluminismo, entonces es importante, por un lado, que todos y todas, sin excepción, tengamos igual oportunidad de acceso a la cultura; lo cual efectivamente no ocurre con las prácticas corporales en nuestras culturas. Por otro lado, es importante reconocer que aquellos universales del iluminismo, que tienen mucho de homogenización, son quizás los responsables de la masificación, que es otra manera de hacer morir la potencia creativa de los individuos singulares, negando la posibilidad de una inflexión en dirección al individuo, tal como propuso Theodor Adorno (1995). Dado el caso, todavía hoy el mundo no es de todos ni para todos, como pretende hacerse ver desde el Gobierno brasilero actual. Precisamente, la Educación Física se ha convertido en un vehículo de afirmación de un mundo de exclusión, de discriminación y de negación de oportunidades, un mundo para algunos, para pocos, centrado en una permanente actualización de formas de exclusión y dominación.

Si esto es efectivamente así, entonces debemos rechazar una organización del área que no considere la diversidad, la pluralidad y la singularidad, sino que, por el contrario, postulamos que debiera promover una cultura y una vida digna para todos. Cuestión que solo es posible si reconocemos las diferencias, no sólo en cuanto a las ideas sino también respecto a las diferencias culturales, corporales. Para nosotros, que trabajamos con la educación del cuerpo, las diferencias son de piel, de gestos, de comportamientos, de maneras, de formas de hablar y decir... son diferencias culturales. Pero son, todavía, de clase, de etnia, de sexo. La alternativa está en que no debemos considerar más la cultura como un hecho universal, pues los "universales" cubrieron mucha violencia, exclusión, discriminación, pudiendo ser la negación de una vida que merezca ser llamada humana. Por tanto, la diferenciación y la universalización de las oportunidades debería ser un aliento para nosotros, los latinoamericanos, que venimos de tradiciones híbridas, mestizas. No somos europeos -aunque la idea misma de "europeo" ya suena extraña-. Pero no está de más recordar que toda la tradición de las disciplinas modernas, incluso la de la Educación Física, es europea, pues de ahí nació lo que hoy conocemos por curriculum (Hamilton, 2001; Goodson, 1995). De ello se desprende que los modelos tradicionales de Educación Física, así como están plantados actualmente, poco pueden contribuir a un cambio radical en las culturas latinoamericanas respecto a la educación -y a las concepciones- del cuerpo.

\section{LA DIFERENCIA Y EL ENTRE-LUGAR}

Por muchos siglos los europeos no aceptaron la idea del otro como diferente, sí, en cambio, como exótico, salvaje o bárbaro. El resultado más evidente de esta forma de 
relación la tenemos en la idea de "colonización", aceptada en nuestro continente como uso corriente para referirse al desembarco de los europeos en Latinoamérica y no como la toma de posesión por asalto de tierras ajenas mediante el uso de violencia extrema, proceso que implicó además producir una representación política del otro como distinto y "no civilizado". Sin embargo, recién ahora se sabe esta distinción, así como sabemos que de distintas maneras muchos pelean contra esa historia, ora para negarla, ora para corregirla, como lo hace el escritor colombiano William Ospina (2008). Lo que se perdió de vista en muchas situaciones fue la complejidad de los encuentros culturales: siempre que nos relacionamos con otra cultura, si no admitimos la diferencia, entonces tendremos problemas para el entendimiento. La Educación Física, aún con sus interpretaciones locales, en tanto herencia del desembarco europeo, cumplió su papel en la afirmación de formas autoritarias de organización cultural. Aliada al status quo siempre estuvo al servicio de los dueños del poder. Se trata, pues, de invertir esta larga tradición y de intentar plantear las bases de otras formas de concebir y hacer Educación Física de acuerdo con los intereses de la mayoría de los pueblos latinoamericanos, pueblos explotados, discriminados y marginalizados, muy distintos entre sí pero con caminos comunes.

Así, escuchando y comprendiendo al otro podremos empezar a reconocer una diferencia esencial: no compartimos la misma cultura común, pero una historia de violencia nos une, tratándose de algo, en definitiva, corporal. La situación, así puesta, puede provocar un bloqueo en nuestras relaciones o puede significar un primer paso adelante en la dirección del otro. No se trata de una formalidad, pero sí de un deseo y de un reconocimiento: el deseo de una comunicación y de integración efectiva y no formal, y el reconocimiento de que somos diferentes en nuestras maneras de comunicar. Compartimos una herencia común de pueblos que todavía siguen bajo nuevas formas de avanzada colonización. Así, esta distinción nos impulsa en dirección a reconocer a los otros: si procuro conocer la cultura que define mi interlocutor entonces necesito hacer un movimiento en esa dirección. Esto es, reconocer la diferencia, aceptar su manera de estar en el mundo sin someterlo a mis imperativos o prejuicios.

Mantenidas las debidas proporciones es posible decir lo mismo del proceso de formación. Este debe permitir que uno se mueva conscientemente en la dirección de lo diferente, de lo desconocido, de lo no-igual, aún para comprender las singularidades. Hoy la Educación Física se convierte cada vez más en una práctica social de personas sin conexión con el mundo exterior, pues sus actividades no miran la integración, sino que segregan, separan, clasifican, como antaño realizaban. En ese sentido, no debería extrañar que muchos jóvenes no les gusten las clases de educción física, pues para ellos se trata de un conjunto de prácticas de violencia y exclusión. Véase lo que registra un chico que se encontraba en los comienzos de la carrera de formación de maestros de Educación Física en el 2005:

¡Yo jamás jugaba! Yo no tenía muchas habilidades y mis amigos no me elegían para sus equipos. A los maestros que yo tuve no les preocupaban si muchos alumnos se quedaban fuera de las clases. ¡Tanto hacía! Lo que deseaban era que los alumnos no los molestaran. Por eso no consigo ver el deporte como algo que promueva la integración. ;Eso es muy relativo! Es como allá, en la escuela donde estudié. La maestra no está preocupada porque los alumnos no saben jugar. Ni mismo pregunta porque los alumnos no quieren participar. Espero que yo pueda ser un profesor diferente que permita que mis alumnos participen de las actividades 
de la clase independientemente de sus habilidades. Ellos no son atletas y el deporte es una forma de conocimiento...

Con el relato de Claudio, alumno del segundo año de la carrera de grado en Educación Física de la Universidad Federal de Paraná, en Brasil, podemos percibir la potencialidad de la memoria para pensar los desafíos cotidianos en las escuelas. Sin condenar el deporte o la escuela por sus connotaciones pretendidamente ideológicas, como comúnmente ocurre, o sin hacer apología del deporte como algo que no puede faltar en los contenidos escolares, el alumno reflexiona sobre su propia experiencia escolar para defender el derecho que supuestamente tienen todos los alumnos de acceder al conocimiento representado por esta práctica social, a lo que significa la práctica de los deportes. Aunque no hayan sido deportistas, los alumnos pueden ser portadores de una memoria marcada por experiencias de dolor y frustración que la práctica deportiva conlleva, aún en las clases de Educación Física. La reflexión de Claudio parece estar motivada por un ambiente que enmarca su proceso de formación como maestro, el cual está mediado por los debates con sus colegas o profesores, quienes sí hacen apología del deporte, así también como por la constante y cotidiana difusión que los medios de comunicación realizan sobre el "mundo deportivo", todo lo cual orienta sus reflexiones y su "deseo de ser" un maestro diferente de aquellos que había encontrado en su tiempo de escuela.

En este punto es preciso reconocer que cuando hablamos de un lugar que no es el mismo que el de nuestro interlocutor la dificultad existe para ambos. Entonces es importante definir otro lugar de interacción, que nos es mi cultura ni la suya, mis intereses o los suyos, mis necesidades o las suyas, sino que es un nuevo espacio de relaciones, un entre-lugar, en la expresión de Homi Bhabha (2005). Un sitio distinto que se pueda convertir en una "zona de contacto" donde puedan valorizarse distintas formas de experiencia. En nuestro caso, distintas maneras de ser y estar corporalmente, enmarcadas por el reconocimiento de la diferencia, algo que no está presente en las experiencias de Claudio en la medida que su reclamo tiene que ver con la imposibilidad de diálogo y de expresión del diferente. Así, se reducen las posibilidades de los alumnos: o se adecua a la norma y se vuelve deportista o renuncia a la posibilidad de participar de las clases de Educación Física.

El entre-lugar es el espacio que compartimos cuando nos encontramos con una cultura que para nosotros es extraña. No es más mi espacio o tu espacio, se trata de nuestro espacio. En éste, los términos de la relación y de la comunicación serán definidos de acuerdo con nuestros intereses, necesidades, expectativas, experiencias. Por ello Claudio imagina poder ser un maestro diferente. Se trata de una nueva experiencia de encuentro, donde vamos a aprender y enseñar mi mundo y tu mundo, mi cultura y tu cultura, mi cuerpo y tu cuerpo. El deseo de saber, de conocer, es nuestro motor en la dirección de una experiencia compartida que no quiere decir alegría, tranquilidad, paz o estabilidad. Antes puede constituirse en su contrario y generar tristeza, inseguridad, temor $\mathrm{u}$ odio. Este encuentro puede ser confortable o desestabilizarnos, lo cual es distinto de la idea general inculcada de armonía, de hermosura o de realización plena (de felicidad o de salud, si se permite) conforme muestra la historia de la Educación Física desde los métodos gimnásticos. El encuentro no es estable y puede incluso resultar doloroso, pero nuestra condición después de esta experiencia será, por supuesto, otra; porque en la medida en que nos abrimos para el encuentro definimos con alguna autonomía los límites que nos proponíamos y los riesgos que correríamos. No es lo que ocurre en las prácticas 
homogéneas de Educación Física en gimnasios, escuelas, calles, plazas, porque ellas parten de un lugar definido por otros de acuerdo con viejas tradiciones, como lo muestra el caso de Claudio. En cambio, el entre-lugar permite entender porqué la vida es como es, no como la deseamos ni como la soñamos, en tanto la participación efectiva de cada uno es una posibilidad de afirmación de su capacidad para tomar decisiones. Es decir, el mundo depende también de la voluntad de los sujetos. Uno de los resultados posibles de este encuentro es entonces el entendimiento una vez que mi movilización se hace consciente por motivación propia. Así, al reconocer al otro como distinto de mí puedo reconocerlo más fácilmente en sus límites, dificultades e idiosincrasias; entonces, él no me es más extraño, sólo diferente, y aquel entre-lugar que definimos juntos se convierte en nuestro lugar compartido no extrañable, algo muy distinto de nuestros lugares originales, pues en él se establece el diálogo y no la representación, como engaño o falseamiento. Ocurre un encuentro, un encuentro de culturas o experiencias que pueda permitir el reconocimiento de la diferencia del otro, con el otro. Un encuentro que genera posibilidades de formación que han sido negadas al largo de la historia -lejana o reciente- de la Educación Física en todo el mundo, especialmente en Latinoamérica.

\section{LA TRADICIÓN SELECTIVA DE LA EDUCACIÓN FÍSICA}

La educación del cuerpo ha sido a lo largo de la historia uno de los rasgos más distintivos de modelos de escuela y de curriculum, aún de aquellos disímiles. Sin embargo, es en el marco de la llamada renovación pedagógica, también conocida como Escuela Nueva, un movimiento plural y no monolítico, que las huellas dejadas por la educación del cuerpo se hicieron especialmente visibles. Esto es, muchos de los dispositivos movilizados para el desarrollo de la educación son eminentemente corporales: la definición de espacios propios, de tiempos demarcados, de actitudes tales como caminar, escribir, sentarse o quedarse en silencio denotan una manera particular de instruir el cuerpo, que a su vez implica formas específicas de sensibilidad.

A lo largo de este proceso pedagógico han surgido nuevas materias o asignaturas de enseñanza, algunas de las cuales fundan su sentido en una manera particular de comprender el cuerpo y la sensibilidad. En otras palabras, el nacimiento del currículum moderno procuró educar los cuerpos y las sensibilidades de distintas maneras y a través de diversas asignaturas, más allá de la Educación Física. Así, la Gimnasia, el Canto, los Trabajos Manuales, la Historia Natural, la Higiene, que estaban presentes en la escuela de fines del siglo XIX y comienzos del XX, fueron resignificadas con el ingreso de nuevos pensamientos pedagógicos. Su contenido era desarrollado en los manuales propios de cada asignatura o en tratados de Urbanidad, Catecismos, Lecciones de Cosas e Informes de inspectores, maestros y autoridades de la educación, materiales que propagaban los beneficios de la educación del cuerpo para la inculcación de una renovada manera de comprender las sensibilidades de acuerdo con un mundo nuevo pretendidamente "moderno" y "civilizado". Más precisamente, un mundo nuevo moderno y civilizado que portaba las marcas de Europa y de Estados Unidos, las cuales deberían ser aplicadas también en suelo latinoaméricano.

Si bien esta particularidad pedagógica se olvida que aquellas prescripciones sobre cómo debería ser educado el cuerpo no eran únicas o naturales, sino que formaban parte 
de un largo proceso de selección cultural; lo cual nos permite retomar la idea de "tradición selectiva". Por caso, en Brasil, este proceso tiene que ver con una graduada sustitución de la gimnasia por el deporte en las escuelas, algo que ocurrió con fuerza desde los años '20 del siglo XX en adelante (Linhales, 2009).

Cuando se defiende la permanencia de algunas formas tradicionales en nuestra área, y se dice que algunos valores o conocimientos son universales y que la gente debería tener acceso a ellos, casi siempre se olvida preguntar quién ha definido a lo largo de la historia la validez de estos saberes, conocimientos o valores. Así, por ejemplo, el crítico galés Raymond Williams (2003), se preguntaba en La larga revolución porqué un inglés debería conocer la geografía de Sudamérica. Para muchos esta pregunta causa horror, pues deberíamos ser capaces, en última instancia, de aprenderlo todo, cumpliendo así con el legado comeniano de "enseñar todo a todos". Ahora bien, sin embargo, cabe preguntarnos las razones por las que nuestros estudiantes deberían conocer cosas sin importancia sobre otras culturas, cuestiones que no son útiles para su formación. Considero, en este sentido, que es relevante que el conocimiento tenga una dimensión práctica, aunque advierto que no es lo mismo que instrumental, que es el peligro al que se enfrentan muchas disciplinas escolares.

En este sentido, si seguimos desarrollando formas de Educación Física basadas en la competencia, en la clasificación o en la jerarquía, entonces estamos siendo partícipes de un mundo de exclusión, destinado sólo para algunos y no para todos. Si es nuestra tarea encargarnos del cuerpo y sus manifestaciones entonces no podemos eludir o esconder los sufridos cuerpos de las poblaciones pobres de nuestro continente, olvidados generalmente por las políticas públicas que prefieren la performance de equipos de alta competencia, Juegos Olímpicos o Copas del Mundo, tal como ocurre actualmente en Brasil, donde la mayoría de la población nada va a ganar con la realización de estos mega-eventos deportivos.

Las prácticas de Educación Física son profundamente universales, globales, en el sentido negativo que conlleva la homogeneidad. Y las evaluaciones internacionales, como el PISA, ${ }^{1}$ son un claro ejemplo. Pero, entonces, cabe preguntar: ¿de qué me sirve un área que se basa en una pobreza de contenidos y prácticas que no pueden ofrecer una vida mejor para todos, sino tan solo para algunos? ¿No deberíamos acaso intentar invertirlos por una Educación Física de características plurales, que permita la realización de una posibilidad plena de acceso a la cultura, no sólo basada en el rendimiento deportivo o atlético? ¿No debería la Educación Física, en tanto campo de actuación e investigación, permitir que los estudiantes conozcan otras culturas, pero, sobre todo, que conozcan su propia cultura, su propio cuerpo, su propia vida? Más aún, en el caso particular latinoamericano, ¿qué podemos aprender de los juegos tradicionales, entendiéndolos como formas particulares de ver y sentir y hacer el cuerpo, el mundo, la cultura, la vida? Juegos tradicionales que fueron solapados por aquellos que vinieron desde Europa o Estados Unidos, sobre todo los juegos deportivos y la gimnasia repleta de estereotipos. Podemos preguntar, en similar sentido, lo mismo sobre los distintos bailes y la rica musicalidad de este fantástico continente sudamericano. ¿Cuándo los enseñamos y los aprendimos en las escuelas, en nuestro cotidiano? ¿Cuándo la Educación Física los valoriza? Aun cuando

1 Sigla en inglés del "Programme for International Student Assessment" ("Programa Internacional para la Evaluación de Estudiantes”), de la "Organización para la Cooperación y el Desarrollo Económico (OCDE). 
comprendamos que sobreviven al mundo globalizado elementos de distintas culturas en cada uno de nuestros países, algo que no se valora en su justa dimensión es el folclore o las danzas tradicionales, las cuales constituyen una cultura viva que forma parte de nuestra constitución mestiza.

Ahora bien, desde la perspectiva planteada, consideramos necesario exponer las posibilidades de un concepto como el de corporalidad, el cual designa:

el conjunto de prácticas corporales del hombre, su expresión creativa, su reconocimiento consciente y su posibilidad de comunicación e interacción en la búsqueda de la humanización de las relaciones de los hombres entre ellos y con la naturaleza... La corporalidad se consubstancia en la práctica social desde las relaciones de lenguaje, poder y trabajo, los cuales son estructurantes de la sociedad (Taborda de Oliveira, 2003: 131).

Se trata de un concepto descriptivo que representa una polisemia importante. Pero es justamente esa polisemia la que invita a superar la reducción de la Educación Física escolar a su dimensión motriz. Por tanto, sin negar que determinados conceptos exijan gran rigor en su planteamiento, considero que el de corporalidad esgrime con suficiente aproximación el entendimiento que la motricidad no puede estar fuera de la corporalidad; y que ésta, a la vez, se inscribe en la dinámica de producción, circulación y apropiación cultural más amplia. Cuando se persiste solamente en el histórico énfasis motriz, entiendo que se hace justamente porque no se comprende que la escuela es un lugar más amplio que las paredes que la encierran, más complejo que la simple fragmentación del saber; es, por el contrario, un lugar de encuentro, lo que implica entender la corporalidad como una posibilidad potencial de formación humana. Así, si consideramos la Educación Física como un conjunto de saberes fundamental para desarrollar un proyecto de formación, este debería tener en cuenta que los cuerpos se encuentran, se extrañan, entran en conflicto, se reconocen y se acercan desde lo que cada individuo es capaz de sentir, producir y criticar en la cultura, teniendo su corporalidad como elemento fundamental de construcción personal y de reconocimiento del otro. De esta manera es preciso reaccionar contra la idea de que la formación en Educación Física pueda darse solamente en unos pocos minutos de clases semanales. Por el contrario, la corporalidad gana densidad axiológica justamente porque va mucho más allá de los restrictivos espacios de las clases, que son solo fragmentos de los múltiples tiempos y espacios donde la corporalidad de los alumnos está presente.

Entonces, queda claro que los contenidos escolares, los cuales son siempre arbitrariamente elegidos en una tradición, son solamente una parte de las posibilidades escolares de relación con la corporalidad. Por el contrario, la escuela debiera ir más allá de los contenidos formales y poner en perspectiva una formación más amplia, más general, más corporal, que no se restrinja a reproducir los clásicos contenidos "juego", "gimnasia" y "deporte". Se trata, en otras palabras, de la experiencia, de favorecerla, de educarla, ya que la experiencia es formativa por excelencia, y se realiza en los encuentros sociales y culturales como algo que permite dar sentido al mundo en que vivimos.

Una mirada histórica demuestra que no es difícil reconocer el peso de las influencias extranjeras en la construcción de los sistemas nacionales de educación en Latinoamérica. Lo mismo puede decirse del surgimiento de la Educación Física en estos países, como en Argentina, un país más adelantado en estos temas, que ya a comienzos del siglo XX desarrollaba la disciplina, tal como Pablo Scharagrodsky y Ángela Aisenstein (2006) han mostrado con el caso de Enrique Romero Brest y las bases del "Sistema Argentino 
de Educación Física", el cual reprodujo un sentido de ciencia concreto, europeo. Por su parte, Colombia y Brasil no tuvieron un sistema nacional de Educación Física formal, pero lo que sí se hizo en estos dos países en términos de educación del cuerpo se realizó a partir de matrices europeas y estadounidenses, como demuestran los estudios de Claudia Ximena Herrera Beltrán (2007), Meily Assbú Linhales (2009), entre otros autores. Resta verificar con nuevas investigaciones si éste ha sido el mismo sentido para todo el resto del continente, si reprodujeron lógicas europeas y si tuvieron interpretaciones locales particulares.

De esta manera, la historia nos muestra que, aunque conozcamos algunos esfuerzos de construcción de métodos nacionales desde prácticas locales -como el caso de la capoeira en Brasil en la lejana década de 1930-, prevalecieron las influencias de los modelos extranjeros, algunos de los cuales permanecen hasta en la actualidad. Esto tiene que ver con lo que conocemos hoy en día como Educación Física y nos muestra cómo nada en el campo es natural, todo es construido histórica y culturalmente desde el punto de vista de algunas personas, grupos o países. Toda la riqueza de las prácticas corporales de cada uno de nuestros países fue olvidada en la definición de lo que sería la Educación Física. Así, desde hace muchas décadas, casi un siglo, lo que llamamos de Educación Física nacional, sea en Argentina, Brasil, Colombia, Uruguay u otros países latinoamericanos, no es más que una adaptación de lo que se conocía como "Educación Física" en los llamados países "centrales" o "desarrollados". La identidad latinoamericana, entonces, se vuelve extranjera y somete pasivamente las prácticas corporales originarias. Claro que si eso fuera correcto, entonces la noción de corporalidad pierde fuerza, una vez que se producen formulas universales de concebir la Educación Física y el cuerpo que es educado en las escuelas. ¿De que vale el encuentro de los cuerpos si son tratados como máquinas que rinden de maneras iguales? ¿Por qué interesaría la diferencia si seguimos tratando los cuerpos como una cosa natural, universal, sin rasgos que permitan la afirmación de individuos que no desarrollen un mínimo de autonomía?

Por supuesto, debemos investigar las distintas formas de apropiación de los modelos extranjeros en nuestros países. Algunos investigadores han mostrado cómo las maneras de apropiación a veces son inventivas y no meras adaptaciones o copias (BAIA, 2012). Pero ello no invalida la presencia extranjera en la definición de lo que es la Educación Física en nuestros países en la actualidad. Se trata, sin embargo, de lugares de disputas o de entre-lugares, y necesitamos verificar los alcances de los impactos, sean "buenos" o "malos". Comprendemos que la historia es el campo de las posibilidades y de las tendencias. Entonces, podría afirmarse que como tal, la Educación Física adoptó acríticamente el legado europeo y olvidó las riquezas de nuestros países. Más aún, este alejamiento de las tradiciones locales provocó que se distancie de las experiencias particulares (problemas, necesidades, expectativas de vida) de la mayor parte de los pueblos del continente, lo cual produjo que muchas de las experiencias resultantes se enmarquen en los cuerpos de las personas que realizan las clases de Educación Física, sin que éstas las representen.

Esta dimensión propiamente histórica ha contribuido para que nuestro campo haya desarrollado una pluralidad de perspectivas conflictivas en la actualidad, pues son frutos de una "tradición selectiva" eurocéntrica. Algunos trabajan en los marcos de la salud y calidad de vida, otros en el desempeño deportivo, en la reeducación, en el ámbito de la sociología, la antropología o la historia. Todos tienen en común que se ocupan, explícita o implícitamente, de distintas maneras de educar el cuerpo, sea por la vía del entrenamiento, 
de la reeducación motriz, del ocio y de la recreación, de la Educación Física escolar o del reconocimiento de los imperativos socio-culturales sobre la definición de lo que es el cuerpo, la salud, el deporte, la vida activa, etc.

Esta convivencia de perspectivas no es tranquila, fundamentalmente a causa de las disputas por el sentido de la disciplina y por los roles profesionales. Es decir, está en pugna la definición del status quo en el área y, a su vez, las relaciones con otras áreas -en Brasil, por ejemplo, algunos investigadores de la Educación Física sueñan un día ser médicos-. También está en juego la disputa por inversiones públicas o privadas, desde los gobiernos o los organismos internacionales. Un ejemplo sencillo de ello lo constituyen las retóricas sobre la importancia de la Copa del Mundo de fútbol o los Juegos Olímpicos en Brasil. Si somos contrarios a esta perspectiva, entonces para algunos estamos en contra del país y de sus intereses, como si fuese una cuestión fundamental para la vida de las personas. Considero una verdadera lástima que se pueda pensar de esta manera, sobre todo en un país donde los chicos mueren abandonados en las calles, donde muchas niñas son prostituidas, donde aumenta la violencia contra mujeres y niños a pasos agigantados. $\mathrm{O}$ sea, en una sociedad y una cultura de violencia donde los cuerpos, más que celebrados, son humillados, golpeados, violados, muertos, aunque, contradictoriamente, sean mercantilizados, vanagloriados o exaltados. Al contrario de lo que se plantea frecuentemente en los medios de comunicación, no vivimos para la calidad de vida, para la vida activa, para una cultura de paz, antes bien, vivimos una cultura de la muerte. Y la Educación Física, aunque trate sobre el cuerpo, parece olvidar ello todo el tiempo, o celebrar su sacrificio, tal como reconoce Alexandre Vaz (1999).

Así, no se puede abdicar de nuestras prácticas la dimensión política. ¡Sería una tontería suponer que todos los que defienden con tanta pasión el deporte lo hacen solamente por amor a éste! Debemos preguntarnos lo que representa para un país con tantos pobres y miserables como Brasil la realización de los Juegos Olímpicos, que moviliza una de las más poderosas industrias del planeta y obliga a transferir recursos públicos a los más ricos, dejando fuera a la mayoría de la población. Así, como he dicho, construir y definir el entre-lugar no significa compartir sin cuestionamientos la perspectiva del otro, adoptarla, sino reconocer en el otro la posibilidad de un interlocutor válido. Aún la crítica de carácter ético y político sobre el quehacer científico ganaría en profundidad si no negáramos la existencia del otro, aunque seamos su adversario simbólico, disputemos su posición en el campo. En ese sentido, pareciera ser que la Educación Física se convierte en el otro cuando se aleja de los problemas del tiempo presente, de la miseria del mundo, de la violencia y de la exclusión. La tarea es, precisamente, combatir ese lugar de "otro" en el que parecen ubicarla, aún cuando esa idea sea parte de nuestra propia área de conocimiento, entendida por algunos como cuestión "natural".

De esta manera, un movimiento de aproximación hacia el otro, de reconocimiento de su especificidad y de sus diferencias, puede dirigirnos hacia el reconocimiento recíproco y el diálogo crítico, abierto y responsable. Ahora bien, esto sólo será posible cuando los propios mecanismos internacionales de evaluación de la formación, de la educación, de la Educación Física y de la producción científica sean lo suficientemente flexibles para reconocer estas diferencias y especificidades. Partiendo de reconocer que aún estos mecanismos no demuestran tal flexibilidad, entonces considero que deberíamos ser capaces de proponer alternativas a los marcos evaluativos y las políticas internacionales de acuerdo con las necesidades de nuestras comunidades en cada país, particulares y 
locales. No debemos olvidar que las pautas de evaluación son definidas en el ámbito de los intereses académicos o científicos de Estados Unidos y Europa. Es decir, repiten la historia, la tradición en la que se enmarcan. Es lícito reconocer que muchos de nuestros pares siguen reproduciendo aquello que dictan los organismos de evaluación e ignoran la pluralidad de lo que sea formación, educación, Educación Física, ciencia o todos los problemas sociales y culturales que enmarcan nuestro continente. Si las aceptamos de manera no-crítica, entonces no queda otra alternativa que admitir nuestra sujeción pasiva y sumisa a sus planteamientos. Pero, en cambio, si procuramos un entre-lugar entre la comunidad científica y profesional, si trabajamos para modificar la relación dominada frente a los modelos de evaluación que se imponen, las potencialidades de construir políticas diferentes se multiplican.

Por otro lado, cabe concebir la cultura como algo fundamentalmente humano. Así, evitamos el riesgo de la negación de algunas conquistas del sujeto, como la cuestión del género, también relevante en los marcos de las prácticas corporales. ¿Quién es Picasso? ¿Es español, francés? ¿Y Botero y Frida Kahlo? ¿Oscar Niemeyer? ¿No son un legado de aquello que los seres humanos han producido? ¿Y las canciones del altiplano boliviano, las guaranias de Paraguay o la artesanía de los pueblos del Amazonas? ¿Y todos los ricos bailes de nuestro continente? ¿No son ellos también expresiones del hombre, expresiones de su cuerpo? Pues, si partimos de comprender que no debemos rechazar nuestra cultura particular -sin rasgo de romanticismo o apego a la tradición-, también es necesario reconocer la importancia del encuentro con otras culturas. No podemos negar lo que Europa nos ha ofrecido a lo largo de la historia. Como pueblos colonizados debemos tener en cuenta críticamente nuestra condición subalterna a lo largo de la historia y ofrecer alternativas al dominio, a la universalización barata de la cultura cuando son planteadas por los europeos o estadounidenses ( $\mathrm{y}$ a veces por nosotros mismos!). Olvidar las buenas cosas de la cultura es algo propio de los regímenes autoritarios. Doblar las rodillas a los modelos de homogenización que vienen de los países que se dicen más desarrollados es un nuevo crimen contra nuestras culturas, pues hay ahí un frágil punto de equilibrio que debemos enfrentar con determinación si queremos que la Educación Física latinoamericana cumpla su papel en la valoración de la vida.

Así, se trata de la búsqueda, una vez más, del entre-lugar. De aquel sitio y tiempo donde podamos establecer la pauta de una agenda que considere lo particular de cada cultura en relación a lo universal, cuestionando profundamente la tradición acrítica de la Educación Física, sea esta tradición europea o estadounidense o de cualquier otro lugar que no valore nuestras propias culturas y todos los problemas seculares que nos definen como pueblos mestizos. Negar lo que han construido estas "culturas" es cometer el error de lo nacional por sustracción, término acuñado por Roberto Schwarz (2001), un intelectual europeo estudioso de las cosas que ocurren en la cultura brasileña. Cuando negamos al otro intentando hacer desaparecer su contribución a nuestra propia cultura, corremos el riesgo de fortalecer populismos de todo orden. Muchas de las dictaduras de Latinoamérica hablaban en nombre de lo nacional y de lo popular. Y lo nacional no era más que los intereses de pocos, de grandes empresas o de las burguesías locales. Considero que deberíamos estimular el intercambio de nuestros alumnos, el conocimiento de diferentes culturas y promover un esfuerzo de comprensión de las diferencias también en el campo de las prácticas corporales, pero en términos culturales más amplios de los que vienen desarrollándose. 
Claro que sabemos de los imperativos económicos que definen nuestro quehacer cotidiano. Y es justamente ésta la clave que me interesa plantear: si la cultura y la economía no están separadas, pareciera ser que se trata de elegir cuál de estas queremos que prevalezca como definidora de las posibles contribuciones de nuestra área en pro de construir una vida más digna para miles de millones de personas. Pues bien, cierto es que la economía ha mostrado, en su matrimonio con la política, que no tiene ganas de cambios profundos, fundamentalmente para los más desamparados. En la Educación Física y en la educación en general, hoy existe una presencia muy fuerte de la economía. Considero que esto debiera preocuparnos, pues nos hemos sometidos sin crítica al canto de las sirenas del mercado, sea el mercado deportivo, el recreativo, el científico o el educativo. Y el mercado no promueve una cultura que valore la vida de todos, ni contempla los entre-lugares, las diferencias, la pluralidad.

Los intercambios culturales tal vez sean una posibilidad para edificar nuevas formas de diálogo entre las diferencias. Mientras que la economía globalizada nos homogeniza, el diálogo cultural nos puede enseñar que otro mundo es posible, sin que ello signifique someterse de manera resignada. No es soportable pensar la formación, sea general o profesional, en Educación Física o en otros campos, solamente en términos de mercado, como se ha hecho históricamente y como continúan haciéndolo muchos de nuestros colegas. Por supuesto sería muy interesante que nuestros alumnos latinoamericanos tuvieran la posibilidad de usufructuar de becas internacionales, como la Erasmus. Pero hay que planear el día que la movilización de estudiantes dentro de Latinoamérica sea tan deseada y estimulada como la movilización de nuestros estudiantes a Europa o a Estados Unidos. Además, hay que soñar con el día que conozcamos muy bien nuestras culturas, más allá de los prejuicios que plantean los medios de comunicación internacionales sobre lo que somos: exotismo, narcotráfico y violencia. Tal vez ello pueda parecer romántico, lo sé. Pero si los términos que se exponen acá tienen que ver con la posibilidad de una vida más digna y menos resignada para nosotros, entonces propongo que construyamos una nueva Educación Física que considere el diálogo entre las tradiciones cientificistas del campo y las múltiples tradiciones culturales y corporales de nuestro continente, ¡у ojala así sea!

\section{AGRADECIMIENTOS}

A Eduardo Galak por la revisón del castellano.

\section{REFERENCIAS BIBLIOGRÁFICAS}

Adorno, T. (1995). Educação e emancipação. São Paulo: Paz e Terra.

Baia, A. (2012). Associação Cristã de Moços no Brasil: um projeto de formação moral, intelectual e física (1890-1929). Tese - Doutorado em Educação. Universidade Federal de Minas Gerais, Brasil.

Bhabha, R. (2005). O local da cultura. Belo Horizonte: Editora da UFMG.

Goodson, Ivor. (1995). Historia del currículum: la construcción social de las disciplinas escolares. Barcelona: Ediciones Pomares-Corredor.

Hamilton, D. (2001). Notas de lugar nenhum: sobre os primórdios da escolarização moderna. Revista Brasileira de História da Educação, Campinas, n. 1, 45-73 
Herrera, C. (2007). Educación física y escuela nueva en la escuela primaria colombiana en el primer tercio del siglo XX. Tesis Doctoral. España: Universidad de Burgos.

Linhales, M. (2009). A escola e o esporte: uma história de práticas culturais. São Paulo: Cortez. Ospina, W. (2008). La escuela de la noche. Bogotá: Grupo Editorial Norma.

Sharagrodsky, P. y Aisenstein, Á. (2006). Tras las huellas de la educación física escolar argentina. Buenos Aires: Prometeo.

Schwarz, R. (2001). Nacional por subtração. En Cultura e política. São Paulo: Paz e Terra.

Taborda De Oliveira, M. (2003). Práticas pedagogicas de Educación Física en los tiempos y en los espacios escolares: ¿la corporalidad como término ausente? En V. Bracht y R. Crisorio (Org.), La Educación Física en el Brasil y en la Argentina: identidad, desafios, perspectivas. La Plata: Ediciones Al Margen.

Vaz, A. (1999). Treinar o corpo, dominar a natureza: notas para uma análise do esporte com base no treinamento corporal. Cadernos Cedes, n. 48, ago.

Williams, R. (2003). La larga revolución. Buenos Aires: Nueva Visión.

Williams, R. (2011). Cultura e materialismo. São Paulo: UNESP. 
